\title{
Correction to: Branched-chain dicationic ionic liquids for fatty acid methyl ester assessment by gas chromatography
}

\author{
Mohsen Talebi $^{1} \cdot$ Rahul A. Patil $^{1} \cdot$ Leonard M. Sidisky $^{2} \cdot$ Alain Berthod $^{3} \cdot$ Daniel W. Armstrong $^{1}$
}

Received: 9 May 2018 / Accepted: 9 May 2018 / Published online: 4 June 2018

(C) Springer-Verlag GmbH Germany, part of Springer Nature 2018

\section{Correction to: Anal Bioanal Chem https://doi.org/10.1007/s00216-017-0722-y}

The authors would like to call the reader's attention to the fact that the original publication included some corrections needed to be addressed.

In the section "Polarity and selectivity with gradient FAME separations" the sentence "IL11 and IL12 are two pyridiniumbased dicationic ILs differing by a methyl group in the middle of the $\mathrm{C}_{5}$ linker confirming the observation made with IL8 and IL9 (Fig. 2) on significant selectivity changes induced by this extra methyl group" should read "IL11 and IL12 are two pyrrolidinium-based dicationic ILs differing by a methyl group in the middle of the $\mathrm{C}_{5}$ linker confirming the observation made with IL8 and IL9 (Fig. 2) on significant selectivity changes induced by this extra methyl group".

Some references were incomplete. The citations [5, 15, 33] should be replaced by the following 3 references:

Published in the topical collection Ionic Liquids as Tunable Materials in (Bio)Analytical Chemistry with guest editors Jared L. Anderson and Kevin D. Clark.

The online version of the original article can be found at https://doi.org/ 10.1007/s00216-017-0722-y

Daniel W. Armstrong

sec4dwa@uta.edu

1 Department of Chemistry and Biochemistry, University of Texas at Arlington, 700 Planetarium Place, Arlington, TX 76019, USA

2 MilliporeSigma, Bellefonte, PA 16823, USA

3 Institut des Sciences Analytiques, Université de Lyon 1, CNRS, 5 rue de la Doua, 69100 Villeurbanne, France
5. Patil RA, Talebi M, Sidisky LM, Armstrong DW. Examination of selectivities of thermally stable geminal dicationic ionic liquids by structural modification. Chromatographia. 2017;80(10):1563-74.

15. Talebi M, Frink LA, Patil RA, Armstrong DW. Examination of the varied and changing ethanol content of commercial Kombucha products. Food Anal Methods. 2017;10(12):4062-7.

33. Talebi M, Patil RA, Armstrong DW. Physicochemical properties of branched-chain dicationic ionic liquids. J Mol Liq. 2018;256:247-55.

On Fig. 1a, b, the boxes on top of each figure should show the complete pair of compounds involved in each series. On Fig. 3, the $X$-axis was misplaced and incomplete. Please find the corrected version of these figures below.

The authors apologize for the mistakes. 


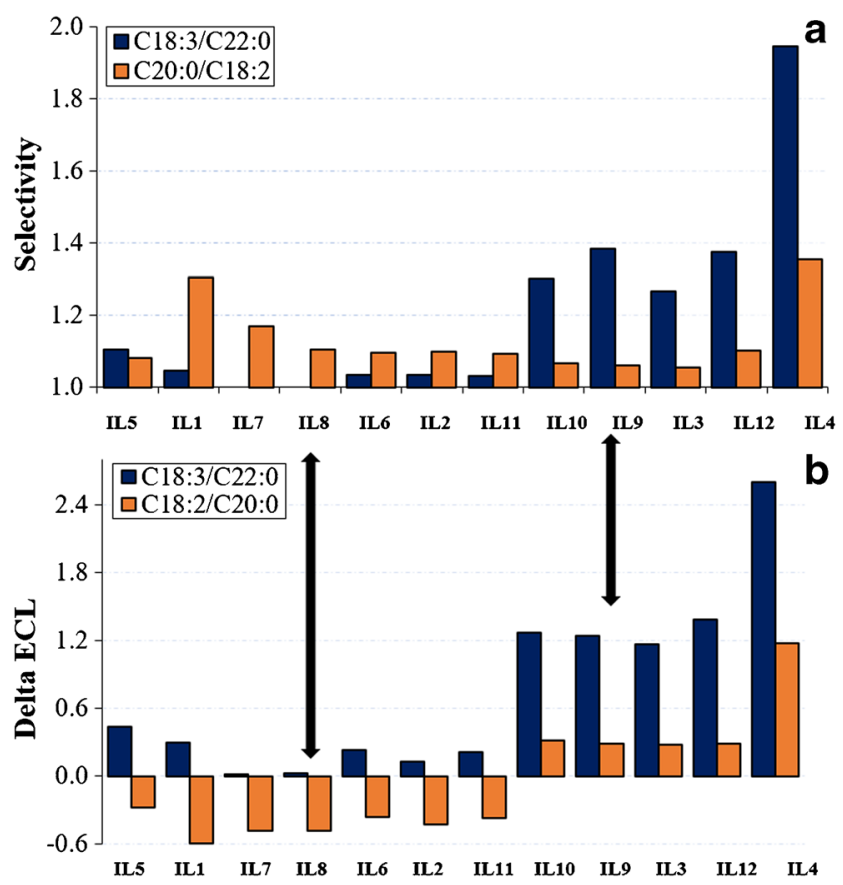

Fig. 1 Comparison of the selectivity obtained with the dicationic ILbased $\mathrm{GC}$ columns in the separation of the methyl esters of linoleic acid and arachidic acid (C18:2 and $\mathrm{C} 20: 0)$ and linolenic acid and behenic acid (C18:3 and $\mathrm{C} 22: 0)$. a Selectivity factors (ratio of the higher retention factor over the lower one). b Equivalent chain length differences. The vertical arrows indicate the two columns whose chromatograms are shown in Fig. 2. The columns are sorted by decreasing polarity order with the most polar IL5 on the left (see Table 1). Columns $30 \mathrm{~m} \times$ $250 \mu \mathrm{m}$, film thickness $20 \mu \mathrm{m}$, helium carrier gas at $1 \mathrm{~mL} / \mathrm{min}, 180^{\circ} \mathrm{C}$

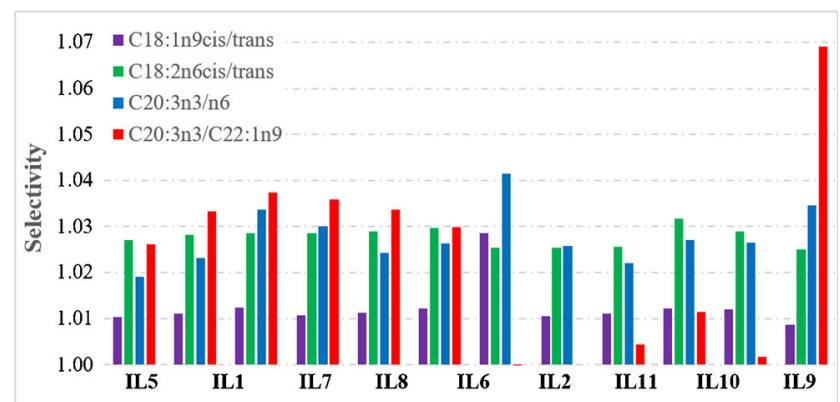

Fig. 3 Comparison of the selectivity obtained with the dicationic ILbased GC columns in the separation of the methyl esters of the cis and trans isomers of $\mathrm{C} 18: \ln 9$ (oleic and elaidic acids), cis and trans isomers of $\mathrm{C} 18: 2 \mathrm{n} 6$ (linoleic acid), C20:3n3 and $\mathrm{n} 6$, and $\mathrm{C} 20: 3 \mathrm{n} 3$ and $\mathrm{C} 22: 1 \mathrm{n} 9$ (erucic acid). The columns are sorted by decreasing polarity order with the most polar IL5 on the left. Columns $30 \mathrm{~m} \times 250 \mu \mathrm{m}$, film thickness $0.2 \mu \mathrm{m}$, helium carrier gas and $1 \mathrm{~mL} / \mathrm{min}, 180{ }^{\circ} \mathrm{C}$ 